\title{
SUSTAINING HAND HYGIENE AND SANITATION CAMPAIGN IN SUB-SAHARAN AFRICA: A GLOWING TRIBUTE TO IGNAZ SEMMELWEIS
}

Godwin T. Jombo,* James O. Tsor, ${ }^{1}$ Alfred Orinya.

Department of Medical Microbiology and Parasitology, College of Health Sciences and ${ }^{I}$ Department of Physics, Faculty of Science, Benue State University Makurdi, Nigeria.

*Corresponding Author: Godwin T. Jombo, Department of Medical Microbiology and Parasitology, College of Health Sciences, Benue State University PMB 102119 Makurdi, Nigeria. Tel: +2348039726398.

Published: November $23^{\text {rd }} 2018$

\begin{abstract}
Ignaz Semmelweis the father of hand hygiene made this startling discovery of strong association of contaminated hands with incidence of puerperal fever and deaths in 1847 and embarked on aggressive campaign to stem the tide of maternal deaths at that time and eventually succumbed to death due to septicaemia in 1865 . At present about 171 years since this discovery, the entire humanity is yet to fully embrace the full practice of hand hygiene and reduce as much as half of the morbidities and mortalities from communicable diseases across the globe. Sub-Saharan Africa remains the last stronghold of millions of avoidable deaths from poor hand hygiene and 156 million people from Nigeria are yet to have access to facilities for hand hygiene. Facilities for hand hygiene should be adequately provided in all hospitals and clinics, schools and all settings experiencing assemblage of crowds while health education and advocacy is stepped. This will serve as a mark of honour to Ignaz Semmelweis, the man that paid the supreme price saving the lives of millions across the globe in defence of hand hygiene.
\end{abstract}

Keywords: Communicable diseases, Hand Hygiene, Ignaz Semmelweis.

\section{Introduction}

It was in 1847 that Ignaz Semelweis an Austrian-Hungarian Medical doctor popularly referred to as the father of hand hygiene was employed at a General hospital in Vienna Austria and made a landmark discovery on association of spread of diseases with hand washing. He compared medical interns who worked on cadavers in autopsy rooms and washed their hands before attending to pregnant women in maternity wards with those who did not wash their hands before doing so. Semmelweis discovered that in the maternity ward where interns and doctors washed their hands before carrying out deliveries, maternal mortality from fatal puerperal sepsis dropped by over 500 percent compared to those who did not wash their hands. The young doctor then postulated that microscopic organisms were present in the hands of those who did not wash their hands before carrying out deliveries which caused high death rate among puerperal women and hence strongly advocated for hand washing. ${ }^{1-4}$

Semmelweis was hotly challenged by his seniors and peers alike who still strongly felt there was no correlation between lack of hand washing and fatal puerperal sepsis in Austrian hospitals and maternity wards and that each incidence had isolated cause. Semmelweis was eventually dismissed from the hospital on account of his insistence and uncompromising stand on hand hygiene, was disowned by his wife, and was later taken to a rehabilitation centre believing he had mental derangement. He later died 1865 from septicaemia arising from gangrenous wounds due to probable severe torture from guards about 12 days after his admission in to the rehab centre at the age of $47 .^{2,3}$

\section{Hand Hygiene}

According to World Health Organization (WHO) hand hygiene refers to any action of hand cleansing. It includes: applying an alcohol-based hand rub to the surface of hands (including liquids, gels and foams); or washing hands with the use of water and soap or a soap solution, either non-antimicrobial or antimicrobial. When performed correctly, hand hygiene results in a reduction of microorganisms on hands. Indications for hand hygiene include: Using an alcohol based hand rub for all clinical situations where hands are visibly clean; Washing with soap and water when visibly dirty or contaminated with proteinaceous material, or visibly soiled with blood or other body fluids, or if exposure to potential spore forming organisms is strongly suspected or proven, or after using the bathroom. $^{5-6}$

\section{Journey towards Improving Hand Hygiene Practices}

For over a century since the discovery of impact of hand hygiene on spread of infectious diseases among humans, it did not receive the serious attention it deserved. It was in 1975 when the Centre for Disease Control (CDC) of America first drew a standard operating procedure (SOP) for hand washing to be implemented in all American hospitals and clinics by healthcare workers. This was further reviewed in 1985 with sustained advocacy. In 1995 upon the wake of widespread multi-drug resistant micro-organisms, the Hospital Infection Control Practices Advisory Committee (HICPAC) strongly recommended the use of antimicrobial soap or a waterless antiseptic agent for cleaning hands upon leaving the rooms of patients infected with such. Due to the growing trend of 
Hospital Acquired Infections (HAIs) the WHO launched the first hand hygiene initiative and advocacy in 2006 under the caption "Hand Hygiene in Health Care". It was on $5^{\text {th }}$ May, 2009, that the WHO comprehensively highlighted the importance of hand hygiene and went further to launch guidelines and tools on hand hygiene to reduce the mortalities and morbidities, and other preventable deaths associated with poor hand hygiene across the globe. ${ }^{7-10}$

\section{Compliance to Hand Hygiene in the $21^{\text {st }}$ Century}

Two decades into $21^{\text {st }}$ century, hand washing and sanitation has received varying acceptability and practices both at the hospital settings and domestic fronts. In most parts of North America, western Europe, Australia and some selected regions in Asia (such as: Japan, Thailand, South Korea, Qatar), studies have shown that only about $45 \%(15 \%-85 \%)$ of health care workers sufficiently wash their hands in terms of adequate soap, water and duration of 15-20 seconds. At domestic settings the figures are much lower where less than $25 \%$ of the populace sufficiently washes their hands after visiting toilet. ${ }^{11,12}$ A large number of the people use only water without soap while those who use soap wash for at most six seconds only. The reasons for non-compliance are largely attributed to lack of sufficient awareness more than availability of hand washing facilities. This is because it has been observed that travelers at international airports across the globe where all these facilities are in abundance still find it difficult to sufficiently wash hands after using the toilet. In a study carried out in India corroborated by a similar study in France, several factors why health personnel fail to wash their hands sufficiently were enumerated as in the table below. ${ }^{13-15}$

Findings from Africa and many other parts of developing world show that compliance to hand hygiene is weak both at the hospital settings as well as in domestic and official settings. It is established that at least $50 \%$ of the 1.4 billion Africans as at today do not wash their hands with sufficient soap and water after visiting the toilet. As much as a quarter (300 million) of the people do not wash their hands at all after visiting toilet, another quarter merely wash only with water without soap ${ }^{16,17}$. Among the $50 \%$ (700 million) that wash with soap, barely 30\% (210 million) sufficiently wash in terms of quantity of soap, quantity and quality of water and duration of washing. In Nigeria alone, it is estimated at least 157 million out of her 180 million people lack access to hand washing facilities. The situation is not much different in health settings where medical and other paramedical students, interns, health personnel and other administrative staff working in health settings do not sufficiently comply with hand washing protocol as outlined by WHO. The WHO recommended procedure for hand washing is as outlined in the figure below. ${ }^{18-20}$

\section{Impact of Poor Hand Hygiene in Africa}

It is estimated that in 2016 alone there were a total of 56.9 million deaths across the globe. While about $70 \%$ of those deaths were from non-communicable diseases in the developed world; the reverse was the case as $70 \%$ of this figure was from communicable diseases from the developing world specifically Africa, Nigeria inclusive. ${ }^{21,22}$ It is to be noted that in the $21^{\mathrm{st}}$ century Africa remains the only surviving strong hold of infections and infestations on planet earth. Majority of the deaths were from typhoid fever, diarrhoeal diseases, tuberculosis, upper and lower respiratory tract infection, urinary tract infections parasitoses, among others. Most of those deaths were avoidable and could have been prevented if only adequate hand hygiene protocol was adhered to at both hospital and domestic levels. Sub-Saharan Africa which accounts for at least $75 \%$ of the entire population of Africa similarly shared favourably at least $75 \%$ of the death burden in Africa. ${ }^{24}$

Table showing Factors affecting compliance to hand hygiene (Courtesy of Mathur P. 2011)

\begin{tabular}{|c|c|c|}
\hline $\begin{array}{l}\text { Health care staff related } \\
\text { factors }\end{array}$ & Clinical factors & $\begin{array}{l}\text { Environmental/institutional/behavioral } \\
\text { other factors }\end{array}$ \\
\hline $\begin{array}{l}\text { Physician status (rather than } \\
\text { a nurse) }\end{array}$ & Working in an intensive-care unit & $\begin{array}{l}\text { Wearing gowns/gloves (beliefs that glove use obviates the nee } \\
\text { for hand hygiene) }\end{array}$ \\
\hline $\begin{array}{l}\text { Nursing assistant status } \\
\text { (rather than a nurse) }\end{array}$ & $\begin{array}{l}\text { Working during the week (versus the } \\
\text { weekend) }\end{array}$ & Hand washing agents causing irritation and dryness \\
\hline Male sex & $\begin{array}{l}\text { If involved in activities with high risk of } \\
\text { cross-transmission }\end{array}$ & $\begin{array}{l}\text { Sinks are inconveniently located/shortage of sinks } \\
\text { Lack of soap and paper towels }\end{array}$ \\
\hline $\begin{array}{l}\text { Lack of role models among } \\
\text { colleagues or superiors }\end{array}$ & $\begin{array}{l}\text { Understaffing, patient overcrowding, } \\
\text { insufficient time }\end{array}$ & Belief of low risk of acquiring infection from patients \\
\hline \multirow{6}{*}{$\begin{array}{l}\text { Not thinking about it/ } \\
\text { forgetfulness }\end{array}$} & Patient needs take priority & Lack of knowledge of guidelines/protocols \\
\hline & $\begin{array}{l}\text { Hand hygiene interferes with health-care } \\
\text { worker relationships with patients }\end{array}$ & Skepticism regarding the value of hand hygiene \\
\hline & & Disagreement with the recommendations \\
\hline & & Lack of institutional priority \\
\hline & & $\begin{array}{l}\text { Lack of active participation in hand-hygiene promotion at } \\
\text { individual or institutional level }\end{array}$ \\
\hline & & $\begin{array}{l}\text { Lack of administrative sanction of non-compliers/rewarding } \\
\text { compliers }\end{array}$ \\
\hline
\end{tabular}




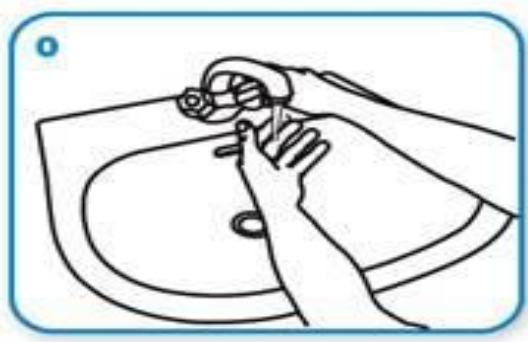

Wet hands with water

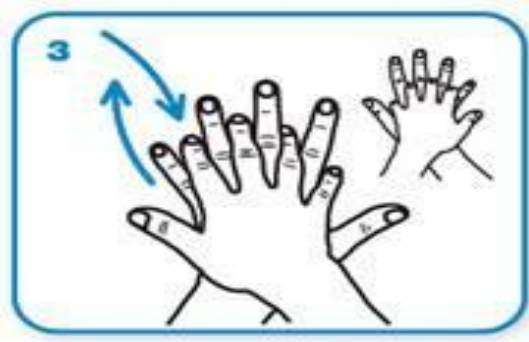

right palm over left dorsum

with interlaced fingers and vice versa

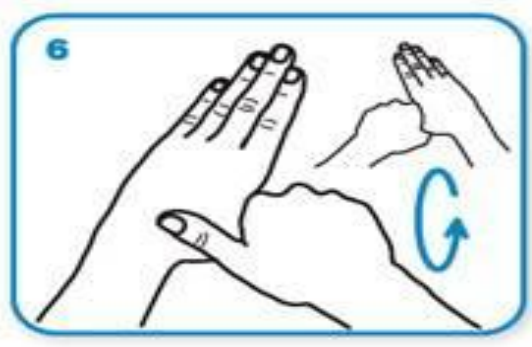

rotational rubbing of left thumb clasped in right palm and vice versa

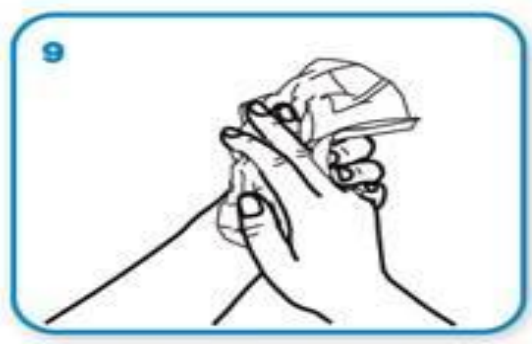

dry thoroughly with a single use towel

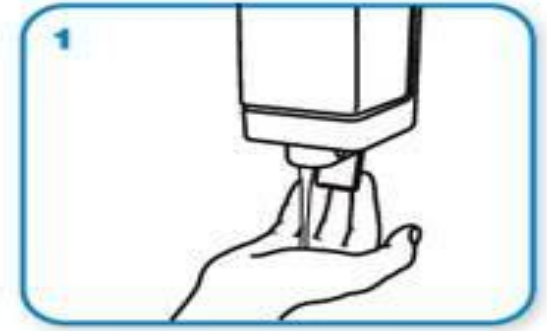

apply enough soap to cover all hand surfaces.

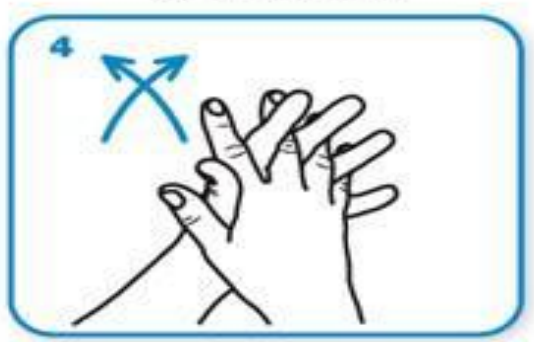

palm to palm with fingers interlaced

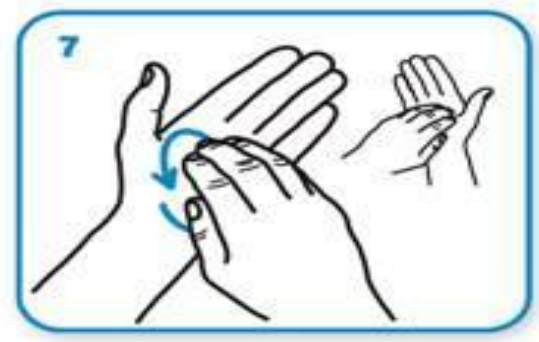

rotational rubbing, backwards and forwards with clasped fingers of right hand in left palm and vice versa.

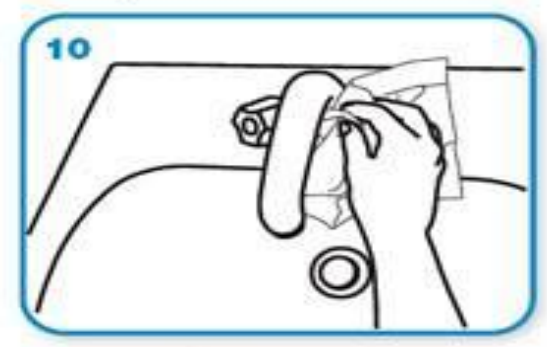

use towel to turn off faucet

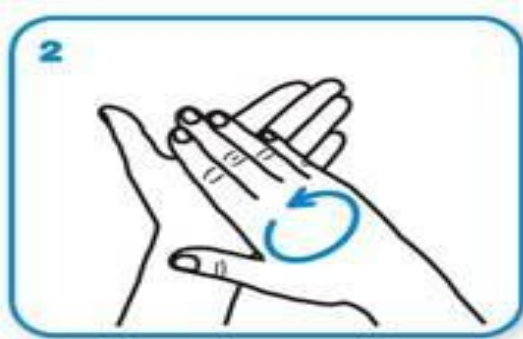

Rub hands paim to paim

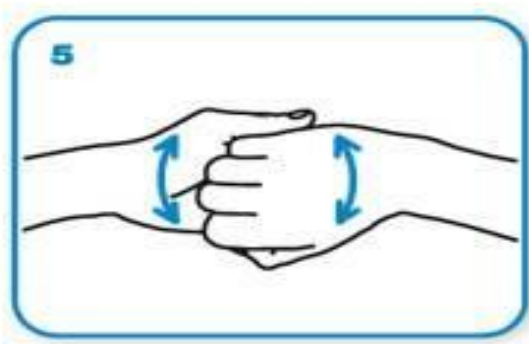

backs of fingers to opposing palms with fingers interlocked

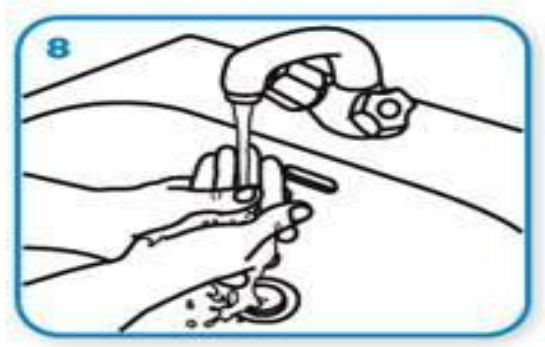

Rinse hands with water

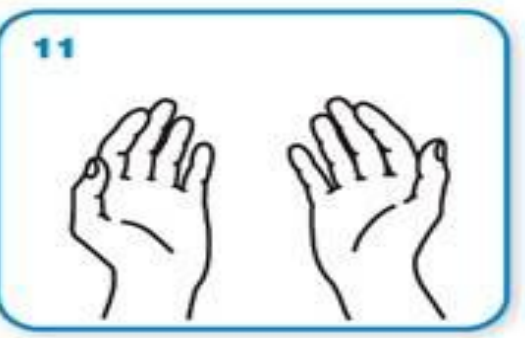

...and your hands are safe.

\section{WHO Recommended Procedure for Hand Washing}

\section{Hand Hygiene and Antimicrobial Resistance}

Over the past three decades there has been a sustained increase in the emergence and resurgence of antimicrobial resistance among micro-organisms at both domestic and hospital settings. Treatment of tuberculosis is increasingly becoming difficult with the emergence of multi-drug resistant (MDR), extensively drug resistant (EDR) and total drug resistant (TDR) Mycobacterium tuberculosis strains. Also the present challenges in the treatment of the 'superbugs' referred to as ESKAPE (Escherichia coli, Klebsiella pneumoniae, Acinetobacter, Pseudomonas 
aeruginosa and Enterococcus) on whose isolation fail to respond to almost all the antibiotics on the pharmacy shop calls for serious concern. ${ }^{25,26}$ Several strains of these organisms among others produce extended-spectrum betaLactamases (ESBL), extensively extended spectrum betaLactamases (EESBL), and pan drug-resistant ESBL. Many of these isolates may fail to be susceptible to all penicillins, cephalosporins, carbapenems as well as meropenems. ${ }^{27-32}$

The present onslaught of methicillin/oxacillin and vancomycin resistant Staphylococcus and Streptococcus species from surgical site infections (SSIs) along with several other isolated cases of pan-drug resistant bacteria have all compounded the physicians' nightmare in the treatment of those infections. ${ }^{33}$ Proper hand hygiene would reduce the spread of these dangerous agents by more than half and the concomitant morbidity associated with loss of man hours, the huge economic losses deployed to managing them, and, the mortalities associated which are unquantifiable.

\section{Way Forward}

Public advocacy and campaign on hand hygiene using soap and adequate water or hand sanitizers should be stepped up in Nigeria and entire sub-Saharan Africa to arrest this ugly trend. Markets, churches, mosques, other social gatherings should be used as avenues to pass the message. The curriculum in schools from nursery primary and secondary schools should feature prominently the emphasis of hand hygiene while the general studies (GST) in the universities, monotechnics, polytechnics and colleges of education should incorporate techniques and procedures for hand hygiene. This should be accompanied with robust practical demonstrations while teachers and lecturers are necessarily encouraged to attend workshops on hand hygiene so as to sufficiently step down to pupils/students. Also nongovernmental, faith-based and community based organizations should complement in the provision of additional infrastructures for hand hygiene (notably flowing tap water, soap and detergents, hand sanitizers, wash hand basins and sinks, water closet toilets and latrines, hand wash stations) in both public and private settings in communities in order to deepen the culture and practice of hand washing. ${ }^{34,35}$

At the hospital level, standard operating procedures (SOPs) on hand washing and use of sanitizers should be mounted on the wall directly on top of all wash hand sinks in theatres, wards, laboratories, clinics, GOPD, A\&E and all other units including the administrative offices. All staff and students should be encouraged to adhere strictly to the prescription of the SOPs and the senior doctors and the leadership of various sections ensures compliance by being compliant. Governments should exhibit strong political will by providing adequate facilities for hand hygiene in schools, hospitals/clinics, ministerial/extraministerial/departments and other settings such as stadia and recreational parks to sufficiently encourage the practice of hand washing. ${ }^{36-38}$

\section{Conclusion}

The campaign on personal hygiene including correct hand washing should be sustained in Nigeria and indeed the entire sub-Saharan Africa. All organizations and institutions including healthcare should key into the current campaign against communicable diseases in the country and Africa as a whole so as to reduce the number of preventable communicable deaths arising from lack of or insufficient hand washing prevalent now on the continent. Ignaz Semmelweis, the progenitor of hand hygiene fought in defence of this great discovery which has saved millions of lives across the globe probably including the authors of this work, and ultimately paid the supreme price. The least humanity can now do to honour this great man after about 150 years of his death is for Sub-Saharan Africa which appears left behind in the practice of hand hygiene is to redouble her efforts and hence catch up with the rest of the world.

\section{References}

1. History.https://www.globalhandwashing.org/abouthandwashing/.Available at this URL, (Aceessed date 25/11/2018)

2. The History of Hand Hygiene: A Tribute to Semmelweis. http://www.handinscan.com/the-history-of-hand-hygiene-atribute-to-semmelweis/.

3. Chai C. Hand washing: 6 steps to kill the germs on your hands. Health. https://www.globalnews.ca/health/.

4. Hand Hygiene Australia. http://www.hha.org.au.

5. Trampuz A, Widmer AF. Hand hygiene: A frequently missed lifesaving opportunity during patient care. Mayo Clin Proc. 2004;79:109-16.

6. Sax H, Uckay I, Richet H, Aegranzi B, Pittet D. Determinants of good adherence to Hand Hygiene among healthcare workers who have extensive exposure to Hand Hygiene campaigns. Infect Control Hosp Epidemiol. 2007;28:1267-74.

7. Guide to implementation of the WHO multimodal hand hygiene improvement strategy. http://www.who.int/patientsafety/en/

8. WHO Guidelines on Hand Hygiene in Health Care. First Global Patient Safety Challenge. Clean Care is Safer Care. http://www.who.int/patientsafety/en/

9. Semmelweis I. Etiology, concept, and prophylaxis of childbed fever. In: Carter KC, editor. 1st ed. Madison, WI: The University of Wisconsin Press; 1983.

10. Health Protection Scotland. National Hand Hygiene NHS Campaign. Compliance with Hand Hygiene - Audit Report. Glasgow, Scotland: Health Protection Scotland,2010.http://www.documents.hps.scot.nhs.uk/hai/infecti on-control/national-hand-hygiene-campaign/audit-report-201003-31.pdf

11. Steere AC, Mallison GF. Handwashing practices for the prevention of nosocomial infections. Ann Intern Med. 1975;83:683-90.

12. Stone SP. Hand hygiene: the case for evidence-based education. J R Soc Med. 2001;94:278-81. 
13. Mathur P. Hand hygiene: Back to the basics of infection control. Indian J Med Res. 2011;134(5): 611-620. doi: [10.4103/09715916.90985].

14. Pittet D. Improving adherence to hand hygiene practice: A multidisciplinary approach. Emerg Infect Dis. 2001;7:234-40.

15. Erasmus V, Brouwer W, van Beeck Ef, Oenema A, Daha T, Richardus JH. A qualitative exploration of reasons for poor hand hygiene among hospital workers: lack of positive role models and of convincing evidence that hand hygiene prevents crossinfection. InfectControl Hosp Epidemiol. 2009;30:415-9.

16. Pickering AJ, Davis J, Blum AG, Scalmanini J, Oyier B, Okoth $\mathrm{G}$, et al. Access to waterless hand sanitizer improves student hand hygiene behavior in primary schools in Nairobi, Kenya. American Journal of Tropical Medicine and Hygiene. 2013;89(3):411-8.

17. Talaat M, Afifi S, Dueger E, El-Ashry N, Marfin A, Kandeel A, et al. Effects of hand hygiene campaigns on incidence of laboratory-confirmed influenza and absenteeism in school children, Cairo, Egypt. Emerging Infectious Diseases. 2011;17(4):619-25.

18. Falaju J, Omolaoye S. $157 \mathrm{~m}$ Nigerians lack access to handwashing facilities, says Wateraid. Nigerian Guardian Newspapers. $15^{\text {th }}$ October 2018.

19. Ogunsola F, Balogun M, Aigbefo S, Oduyebo O, Oladele R, Olufema J, Ajieroh V. Perception and practice of handwashing in Kuramo community Lagos, Nigeria. Intern J Infect Control. 2013;9:1-8.

20. WHO Guidelines on Hand Hygiene in Health Care (Advanced Draft): A Summary. World Health Organization; 2005.

21. Boubacar Maïnassara H, Tohon Z. Assessing the health impact of the following measures in schools in Maradi (Niger): Construction of latrines, clean water supply, establishment of hand washing stations, and health education. Journal of Parasitology Research. 2014;2014:190451.

22. Curtis V, Kanki B, Cousen S, Diallo I, Kpozehouen A, Sangaré $\mathrm{M}$, et al. Evidence of behaviour change following a hygiene promotion programme in Burkina Faso. Bulletin of the World Health Organization. 2001;79(6):518-27.

23. Pittet D, Allegranzi B, Storr J, Bagheri Nejad S, Dziekan G, Leotsakos A. Infection control as a major World Health Organization priority for developing countries. J Hosp Infect. 2008;68:285-92.

24. Allegranzi B, Sax H, Bengaly L, Richet H, Minta DK, Chraiti MN. Successful implementation of the World Health Organization hand hygiene improvement strategy in a referral hospital in Mali, Africa. Infect Control Hosp Epidemiol. 2010;31:133-41.

25. De Kraker ME, Jarlier V, Monen JC, Heuer OE, van de Sande $\mathrm{N}$, Grundmann $\mathrm{H}$. The changing epidemiology of bacteraemias in Europe: trends from the European Antimicrobial Resistance Surveillance System. Clin Microbiol Infect. 2013;19(9):860-868. doi: 10.1111/1469-0691.12028.

26. Jombo GTA, Peters EJ, Gyuse AN, Mwankon JP. Outcome of directly observed therapy short course (DOTS) regimen in a rural community of the Nigerian Niger delta. Nigerian Journal of Medicine 2008; 17(1): 61-66.

27. Jombo GTA, Ayilara AO, Bello K, Dakum NK,Enenebeaku MNO. Antimirobial susceptibility profiles of uropathogenic bacterial isolates from community- and hospital-acquired urinary tract infections in Yobe state, Nigeria. Journal of Medical Laboratory Science 2005;14(2):54-61.

28. Jombo GTA, Egah DZ, Ayeni JA. Antibiotic susceptibility patterns of bacterial isolates from urine samples of acquired immunodeficiency syndrome (AIDS) patients in Jos, Nigeria. Mary Slessor Journal of Medicine 2006; 6(2): 40-49.
29. Jombo GTA, Ayeni JA, Danung M, Egah DZ. Isolation of Proteus mirabilis from clinical urogenital samples: a study of the antibiotic susceptibility pattern of 392 consecutively isolated strains in Jos, Nigeria. Journal of Medical Laboratory science 2006; 15(1):23-32.

30. Jombo GTA, Jonah P, Ayeni JA. Multidrug-resistant Pseudomonas aeruginosa in contemporary medical practice: findings from urinary isolates at a Nigerian University teaching hospital. Nigerian Journal of Physiological Sciences 2008;23(1\&2):105-109.

31. Jombo GTA, Philip-Ephraim EE, Utsalo SI, Ejezie GC, Enenebeaku MNO Mbaawuaga EM. Quinolones and their clinical relevance in the management of enteric fevers in the new millennium: findings from a review of 55,853 Salmonella species. Global Journal of Medical Sciences 2008;7(1\&2):1-7.

32. Jombo GTA, Akpan S, Epoke J, Denen-Akaa P, Odey F. Multidrug resistant Pseudomonas aeruginosa infections complicating surgical wounds and the potential challenges in managing postoperative wound infections: University of Calabar teaching hospital experience. Asian Pacific Journal of Tropical Medicine 2010;3(6):479-482.

33. Goto M, Al-Hasan MN. Overall burden of bloodstream infection and nosocomial bloodstream infection in North America and Europe. Clin Microbiol Infect. 2013;19(6):501-509.

34. Suchitra JB, Lakshmi Devi N. Impact of education on knowledge, attitudes and practices among various categories of healthcare workers on nosocomial infections. Indian $\mathrm{J}$ Med Microbiol. 2007;25:181-7.

35. Karabey S, Ay P, Derbentli S, Nakıpoğlu Y, Esen F. Handwashing frequencies in an intensive care unit: J Hosp Infect. 2002;50:36-41.

36. Alp E, Ozturk A, Guven M, Celik I, Doganay M, Voss A. Importance of structured training programs and good role models in hand hygiene in developing countries. J Infect Public Health. 2011; 4(2):80-90.

37. Idowu OA, rowland SA. Oral fecal parasites and personal hygiene of food handlers in Abeokuta, Nigeria. Afr Health Sci 2006;6(3):160-164 